\title{
Resenha
}

\section{Direito à saúde: institucionalização}

\section{Review}

Right to health: institutionalization

Reseña

Derecho a la salud: institucionalización

\section{Ana Lucia Brochier Kist ${ }^{1}$}

O primeiro livro da coletânea Direito à Saúde, Institucionalização, reúne ensaios de expertos no tema, como profissionais ligados à gestão do sistema de saúde, à justiça e às pesquisas acadêmicas, que se voltam para um estudo do conjunto normativo encarregado de positivar o direito à saúde. Um instituto que constitui matéria constitucional e, portanto, encontra-se no topo da ordem normativa, resguardado como um direito de todos e dever do Estado. Ainda assim, o Estado encontra-se diante do desafio permanente de superar os obstáculos que se contrapõem à real efetivação do direito à saúde.

A partir da análise dos especialistas que contribuem para a obra, publicada pelo Conselho Nacional de Secretários de Saúde (Conass), é possível compreender o panorama geral que norteia as reflexões sobre o direito à saúde, que pode orientar gestores, profissionais da saúde, administradores da Justiça, assim como todos que se dedicam ao tema.

Cruzando-se as temáticas, identifica-se um eixo em comum, que insere o direito à saúde na categoria dos direitos humanos, relacionando-o ao princípio da dignidade da pessoa humana e ao direito fundamental à vida.

Já no início do livro, o leitor é esclarecido pela análise realizada por Cunha (1) a respeito da aplicação, no Brasil, da teoria doutrinária do mínimo existencial - oriunda do direito constitucional alemão. Para o autor, enquanto na Alemanha o mínimo existencial constituía um instrumento de salvaguarda da dignidade humana, no Brasil, por uma

\footnotetext{
${ }^{1}$ Graduada em Jornalismo pela Universidade Federal do Rio Grande do Sul (UFRGS); graduanda em Direito pela UFRGS. E-mail: analuciakist@gmail.com
} 
construção consciente ou inconsciente, representa um retrocesso social em relação ao direito à saúde.

Segundo Cunha, o debate acerca do mínimo existencial é recente no Brasil, prevalecendo, na doutrina, a imagem de que não há elementos concretos para efetivar todos os direitos a todas as pessoas, embora a erradicação da total desigualdade seja um dos objetivos e fundamentos do estado democrático de direito brasileiro.

Mesmo sem referir o mínimo existencial, o ensaio de Vilaça e Rey Filho (2) relacionase ao tema, na medida em que reconhece, aos cidadãos, o direito de exigir do Estado condições para o completo bem-estar físico, social e mental, considerando, nessa argumentação, o conceito de saúde preconizado pelo preâmbulo da Constituição da Organização Mundial da Saúde de 1946. Esse direito é analisado em relação às dimensões do Brasil, onde o sistema de saúde tem a meta de ofertar assistência à saúde para mais de 200 milhões de pessoas.

Quando interpretam o significado do artigo 196 da Constituição Federal de 1988, que estabelece que a saúde é um direito de todos e dever do Estado, Vilaça e Rey Filho destacam a diferença entre o positivado pelo legislador brasileiro - direito à saúde enquanto direito fundamental de aplicabilidade inquestionável haja vista a proteção à vida - e o que rezam constituições de outros países com sistemas universais de saúde que não garantem o direito à saúde, mas o direito aos serviços de saúde.

A constatação final é que o direito à saúde é um direito vital, fundamental e humano, e que a política de saúde, considerada como política social, enseja a responsabilidade de que a saúde é um dos direitos inerentes à cidadania.

Sob a perspectiva de gênero, a garantia do direito à saúde é entendida como direito social e um direito público subjetivo, que traz implícita a questão da justiça distributiva. Marques (3) defende que a construção de um sistema de saúde efetivamente integral e universal exige a igualdade de gênero, com a consequente garantia do direito à saúde das mulheres.

Ribeiro (4) analisa os direitos da pessoa transgênero a partir da universalidade dos direitos humanos, pela defesa da desnecessidade da cirurgia de transgenitalização para reconhecimento da alteração do nome e do sexo jurídico. Ainda sobre a pessoa transgênero, Castro e Marques afirmam que "as conquistas de acesso à saúde para a população 
transgênero são resultado de um histórico de lutas e articulações da sociedade civil organizada com o Estado". (5, p.281).

Os direitos das pessoas usuárias de serviços de saúde mental são problematizados por Schulman, em uma discussão sobre os fundamentos da internação forçada, involuntária ou compulsória, caracterizada pelo autor como "uma possível apropriação da saúde pelo direito" (6, p.248). A crítica é voltada, especialmente, às práticas estabelecidas no campo penal, por meio das medidas de segurança.

A publicação contempla, também, aspectos internacionais do direito à saúde, analisando a judicialização da saúde na Colômbia, respaldada pela ação de tutela denominada recurso de amparo na maioria dos países da América Latina - e a tutela dos direitos econômicos, sociais e culturais pela Corte Interamericana de Direitos Humanos $(\mathrm{CIDH})$.

Na Colômbia, a constatação de Gómez-Ceballos, Craveiro e Gonçalves (7) é que o sucesso da judicialização da saúde nos tribunais não é garantia de acesso aos cuidados de saúde, pois as seguradoras não cumprem as sentenças judiciais.

Ao analisar o caso Lagos Del Campo Versus Perú, Costa (8) estuda a recente decisão $\mathrm{CIDH}$ à luz dos Direitos Econômicos, Sociais e Culturais (DESCA), da Convenção Americana sobre Direitos Humanos e do Protocolo de San Salvador, ressaltando a virada que a sentença representa, criando um precedente para a plena justiciabilidade dos DESCA.

Da necessidade de proteger a vida humana e garantir sua qualidade e condição, provêm a proteção e melhoria do ambiente do ser humano. Esta relação é aprofundada por Faria (9), ao relacionar direito sanitário e direito do ambiente, considerando-os uma questão de salvaguarda do direito fundamental à vida, agregada aos princípios fundamentais da igualdade e da dignidade humana. Para Faria, o direito sanitário deve ser tratado também como uma questão de saúde ambiental, uma vez que o ser humano, inserido no contexto ecológico, depende de um ambiente sadio para ter saúde e qualidade de vida.

Em outro eixo, podem-se inter-relacionar artigos que abordam a saúde sob a ótica do controle social no estado democrático de direito, que conjuga elementos de representação política e de participação direta dos cidadãos nos assuntos do Estado. Nesse contexto, a participação social no Sistema Único de Saúde (SUS) foi inserida na Constituição Federal de 1988 com o propósito de ampliar a democracia para além do regime meramente 
representativo, legitimando espaços de participação e controle da sociedade sobre os atos do governo.

A diretriz constitucional de participação social no SUS é aprofundada por Campos e Salgado (10), ao discutirem os conceitos de participação e controle social no ordenamento jurídico brasileiro e suas aplicações, por meio dos institutos adotados no SUS. Os autores desenvolvem uma reflexão acerca do papel e dos poderes concedidos aos conselhos de saúde e, em especial, ao Conselho Nacional de Saúde, nos processos de formulação, avaliação e controle das políticas públicas de saúde, a partir de seus marcos legais e normativos.

Por um lado, "a saúde é um dos setores que mais têm investido e evoluído no país, no período pós-Constituição de 1988, em direção à abertura de espaços políticos qualificados nas instâncias gestoras das políticas públicas". (10, p.53). Por outro lado, Campos e Salgado consideram que as desigualdades socioeconômicas se traduzem em desigualdades políticas, refletindo na falta de equilíbrio e de representatividade dos canais de participação dos cidadãos na gestão do SUS. "Participação e controle social são discursos positivos e elegantes nas agendas políticas dos governos, mas sua efetivação, além de cara e morosa, é carregada de conflitos [...]". (10. p.54).

A conclusão desses autores é que a democracia brasileira convive com o paradoxo de ter que absorver e vivenciar os paradigmas da igualdade política, da participação e do controle social e superar os traços culturais de apatia e submissão que caracterizam grande parte da população.

Avelino (11) desenvolve uma discussão da natureza jurídica da participação da comunidade na organização das ações e serviços de saúde. O autor sugere que a atuação do Conselho Nacional de Saúde - espaço previsto na Constituição para exercício da participação social no controle do SUS - é, na prática, inócua ou controlável, visto que há uma relação de subordinação entre o órgão colegiado e o Ministério da Saúde, o que "inviabiliza o exercício autônomo do direito de controle legalmente previsto". (11, p. 78).

Essa subordinação é interpretada com base em uma vedação legal à autoexecutoriedade das resoluções do Conselho, as quais se submetem, como atos administrativos compostos, à negativa de homologação ou omissão do órgão ministerial.

Utilizando-se do samba para associar a irreverência nacional ao Sistema Único de Saúde, Gebran Neto (12) aponta as falhas que ainda existem na prestação de serviços de 
saúde no âmbito da atenção primária do SUS, apesar de avanços conquistados em seus 30 anos de existência. $\mathrm{O}$ autor recomenda que a orientação de uma adequada política pública deve estar voltada aos objetivos constitucionais de diminuição das desigualdades sociais e melhor integração das pessoas mais necessitadas.

Os desafios enfrentados no provimento de financiamento público para a garantia do direito universal à saúde são o pano de fundo para a análise dos efeitos da EC 95/2016, que limita as despesas públicas primárias por 20 anos. Moretti e Menezes (13) calculam os impactos da restrição orçamentária e, para eles, a EC 95 é "disfuncional", pois "a escolha alocativa, aliada à ampliação da receita, não ocorre em função da demanda da população ou da realização de direitos, mas das ações que a Constituição retira do teto de gastos". (13, p.191).

A idealização constitucional do Sistema Único de Saúde como uma única rede interfederativa de serviços hierarquizados, de responsabilidade da União, estados, Distrito Federal e municípios, enseja conflitos e dúvidas na gestão realizada pelos entes federativos, que dividem a atribuição de garantir o direito à saúde por meio da prestação dos serviços de saúde. A questão é elucidada por Mapelli Júnior (14), que realiza uma revisão da jurisprudência e da doutrina - as quais vêm reconhecendo a responsabilidade solidária dos gestores públicos na disponibilização de qualquer prestação sanitária -, debruçando-se sobre o papel dos estados na gestão. O autor reconhece, no Estado, um papel fundamental no SUS, "como planejador regional, organizador e prestador de serviços, com especial relevância na condução do planejamento ascendente e regional" (14, p.123), para além da prestação direta dos serviços sanitários dos municípios e do papel planejador e financiador da União.

Inserindo o debate da regionalização da saúde em um contexto no qual há tensão entre descentralização e integração, Menezes e Chioro (15) demonstram que a institucionalização da regionalização e do pacto intergovernamental ainda carece de revisão, apesar dos avanços observados recentemente no arcabouço normativo do SUS.

Outro aspecto que surge como suscetível a conflitos é a relação entre os administradores públicos e os órgãos de controle. Correlacionando a função de administrar do Poder Executivo e a ciência da administração de empresas, Paixão (16) demonstra que, tanto a gestão pública quanto a gestão privada, estão submetidas ao princípio da imprevisibilidade e da contingência, e que o desafio do Estado contemporâneo é criar 
mecanismos de gestão que permitam a atuação eficiente e autônoma do administrador, com o controle visando a resguardar o erário.

A participação da iniciativa privada no sistema público de saúde, prevista pelo legislador na Constituição de 1988, está presente no modelo adotado atualmente pelo SUS, para fazer cumprir o dispositivo constitucional que impõe à União, aos estados, ao Distrito Federal e aos municípios o dever de prestar assistência à saúde, seguindo os princípios norteadores da universalidade e da integralidade. Aguiar e Gonçalves (17) abordam os elementos envolvidos na contratação de serviços privados de saúde, de forma complementar à rede pública, recomendando que os gestores disponibilizem recursos assistenciais para atendimento das necessidades dos cidadãos em local adequado e tempo oportuno.

Ainda no âmbito da disponibilidade da assistência, as tecnologias empregadas na operacionalização do acesso ao SUS são mapeadas por Silva (18), em um levantamento do conhecimento produzido sobre o tema, indicando uma necessidade de atualização da Política Nacional de Regulação do SUS, com a inclusão dos trabalhadores e serviços no processo de decisão, visando ao atendimento das necessidades de saúde da população.

O tema segurança do paciente é apresentado como um atributo da qualidade do cuidado em saúde e como fator a ser observado pelas esferas do direito diante das demandas judiciais. André, Gonçalves e Amaral (19) observam que a prestação de cuidados de saúde de forma segura ainda é um desafio a ser perseguido pelo sistema de saúde brasileiro. Alves, Sousa e Faria (20) sugerem a ampliação do debate da segurança do paciente para as esferas jurídicas e legais, com a inclusão de advogados, magistrados e legisladores na agenda de discussões.

Entre o direito e a prudência, Buvinich e Oliveira (21) problematizam, de um lado, a salvaguarda de informações pessoais e, de outro, a cautela da adequada comunicação de risco à população. A Lei de Acesso à Informação, de 18 de novembro de 2011, que regulamentou o direito à informação, é considerada um avanço na consolidação conjunta do acesso à informação e do resguardo da intimidade.

Ao mesmo tempo em que reconhecem o protagonismo da saúde na agenda brasileira de desenvolvimento, gerando emprego e renda, os ensaios demonstram a preocupação com a fragilidade da base produtiva e tecnológica em saúde diante das pressões do mercado (2223). Oliveira, Brito e Prado (22) analisam as discussões de propriedade intelectual em saúde pública na Organização Mundial da Saúde (OMS), entre 2006 e 2016, definindo a 
diversificação da produção e a manutenção das indústrias nacionais como "imprescindível para o SUS" (22, p.202).

O novo aparato legislativo referente à Ciência, Tecnologia e Inovação (CT\&l), promulgado a partir de 2015, é projetado por Martins, Rosa e Martins (23) sobre os cenários para o horizonte de 15 anos, até 2030. O estudo prospectivo identifica incertezas críticas, recomendando o afastamento da ICT pública do cenário da ciência para o mercado, em que a estagnação da produção nacional de conhecimento leva à abertura para o capital estrangeiro.

Encerrando a publicação, Santos, Hartz e Delduque (24) abordam o entendimento relativo à lei como intervenção na saúde, a partir da conexão entre saúde, direito e avaliação. As autoras partem do pressuposto que o legislador, ao determinar o que é direito, "impõe responsabilidades para que ele [...] torne-se prestação positiva. Por conseguinte, a lei impõe uma transformação, seja para o indivíduo, seja para a sociedade" (24, p.315).

No que tange ao direito à saúde, reconhecido como direito humano, os ensaios reunidos na publicação, ainda que enxergando o tema por perspectivas distintas, convergem para o desafio constante que representa, para o estado democrático de direito, a prestação positiva do direito à saúde, na plenitude de seu significado.

Santos AO, Lopes LT (org.). Coletânea direito à saúde: institucionalização. Brasília: CONASS; 2018.

\section{Referências}

1. Cunha JRA. O mínimo existencial como retrocesso sanitário para a efetivação do direito à saúde no Brasil. In: Santos $A O$, Lopes $L T$, organizadores. Coletânea direito à saúde: institucionalização. Brasília: CONASS; 2018. p.12-21.

2. Vilaça DSS, Rey Filho M. A saúde para além do Artigo 196 da Constituição de 1988. Ibidem. p.56-68.

3. Marques SB. A garantia do direito sanitário sob a perspectiva de gênero: desafios e enfrentamentos perante o Sistema Único de Saúde para a garantia do direito à saúde das mulheres. Ibidem. p.220-234.

4. Ribeiro IV. A desnecessidade da cirurgia de transgenitalização para o reconhecimento da alteração do nome e do sexo jurídico fundado na universalidade dos direitos humanos e tratamento institucional dado ao tema pelos poderes instituídos. Ibidem. p.261-271. 
5. Castro AF, Marques SB. Direito sanitário da população transgênero: uma construção contemporânea. Ibidem. p.272-283.

6. Schulman G. Internações forçadas e saúde mental: entre tratamento e punição. Ibidem. p.248-259.

7. Gómez-Ceballos DA, Craveiro IMR, Gonçalves LAP. A importância da judicialização da saúde na garantia do direito à saúde em Medellín-Colômbia. Ibidem. p.82-93.

8. Costa TMB. A justiciabilidade dos direitos sociais, econômicos e culturais: caso Lagos del Campo versus Perú. Ibidem. p.22-34.

9. Faria RF. Direito sanitário e direito do ambiente: uma questão de salvaguarda do direito fundamental à vida. Ibidem. p.36-43.

10. Campos TLC, Salgado VAB. A diretriz constitucional de participação social no SUS. lbidem. p.44-54.

11. Avelino DP. Participação da comunidade no Sistema Único de Saúde: juridicidade e controle. Ibidem. p.68-81.

12. Gebran Neto JP. A Atenção Primária à Saúde: um enredo para o SUS. Ibidem. p.95-107.

13. Moretti $B$, Menezes APR. Orçamento como instrumento para realização do direito à saúde? EC 95 e a LOA 2018. Ibidem. p.182-191.

14. Mapelli Junior R. O Estado como gestor de serviços no SUS: regime jurídico e implicações práticas. Ibidem. p.108-124.

15. Menezes APR, Chioro A. Os Estados e os desafios da regionalização da saúde. Ibidem. p.137-146.

16. Paixão ALS. Entre acertos e exageros: a difícil relação entre o administrador público e os órgãos de controle. Ibidem. p.206-219.

17. Aguiar LOF, Gonçalves CC. Contratação de serviços complementares no Sistema Único de Saúde. Ibidem. p.148-164.

18. Silva JMB. Por uma regulação do acesso mais sistêmica e produtora do cuidado: uma reflexão sobre a Política Nacional de Regulação do SUS e a articulação entre as centrais de regulação e os serviços. Ibidem. p.126-134.

19. André CU, Gonçalves CCM, Amaral TCL. O papel da segurança do paciente na qualidade do cuidado em saúde e na concessão do direito à saúde pela via da judicialização. Ibidem. p.236-246. 
20. Alves EAV, Sousa P, Faria PL. Desafios Jurídicos do reporte de eventos adversos: proposta de agenda para a melhoria da segurança do paciente. Ibidem. p.294-306.

21. Buvinich DPR, Oliveira PC. Acesso à informação e comunicação de risco em saúde: entre o direito e a prudência. Ibidem. p.284-293.

22. Oliveira LFC, Brito PT, Prado EAJ. Patentes, inovação e direito à saúde: análise sobre as discussões de propriedade intelectual em saúde pública na Organização Mundial da Saúde entre 2006 e 2016. Ibidem. p.192-205.

23. Martins WJ, Rosa SO, Martins CSF. As mudanças legais para o ambiente da ciência, tecnologia e inovação (Lei 13.243/2016) e seus reflexos para o Sistema Único de Saúde. Ibidem. p.166-180.

24. Santos $A O$, Hartz Z, Delduque MC. Pensar a lei como intervenção no processo avaliativo do direito à saúde. Ibidem. p.309-320. 